\title{
Drilling: medical indications and surgical technique
}

\author{
Cristina Kallás Hueb ${ }^{1 *}$, João Antônio Dias Júnior ${ }^{2}$, Maurício Simões Abrão ${ }^{3}$, Elias Kallás Filho ${ }^{4}$ \\ ${ }^{1} \mathrm{PhD}$ - Specialist in Gynecology and Obstetrics, Faculdade de Medicina, Universidade de São Paulo, São Paulo, SP, Brazil \\ ${ }^{2}$ PhD - Medical Coordinator at Centro de Reprodução Assistida, Hospital Sírio Libanês, São Paulo, SP, Brazil \\ ${ }^{3}$ Habilitation (BR: Livre Docência) - Associate Professor at Faculdade de Medicina, Universidade de São Paulo, São Paulo, SP, Brazil \\ ${ }^{4}$ Postdoctor - Full Professor at Faculdade de Direito do Sul de Minas, Pouso Alegre, MG, Brazil
}

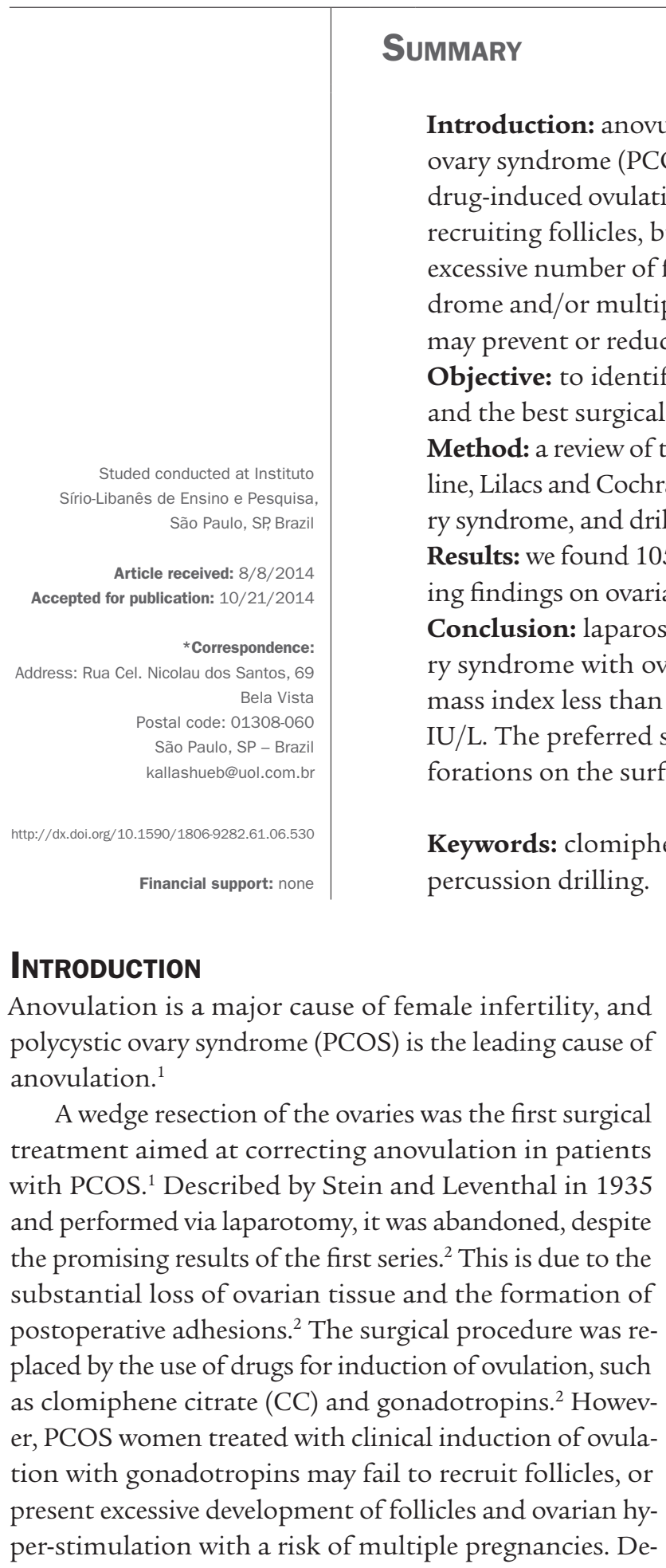

spite being very effective, the use of gonadotropins is expensive, time-consuming and requires intensive monitoring. ${ }^{1}$ Therefore, a modern and less traumatic surgical version compared with wedge resection of the ovaries has been developed using laparoscopy. This procedure known as laparoscopic drilling (LD) of the ovaries probably reduces the need for clinical induction of ovulation, or facilitates its use. ${ }^{1}$ The procedure can be performed with admission in "day hospitals", with very little surgical trauma compared to the initial laparotomy technique. Laparoscopic drilling is a minimally invasive surgery in which the ovaries are treated with small perforations using heat or laser. ${ }^{1}$ The mechanism by which partial destruction results in ovarian follicular development and ovulation is unknown. Despite the contribution of hormonal changes caused by the procedure, such as the reduction of serum androgens, it is not clear whether this 
is the basis of the ovulation restoration mechanism. The most plausible theory involves the sharp drop in intraovarian androgens (and perhaps estrogens) resulting in an increase in the secretion of follicle-stimulating hormone (FSH) and an intra-follicular environment more conducive to normal follicular maturation and ovulation. ${ }^{1}$

From a public health perspective, laparoscopic drilling might serve as an effective option for the development of policies, providing access of patients to a constitutional right to family planning, given that it is an alternative treatment for female infertility that does not require excessively large investments in human resources, infrastructure and technology.

\section{Objective}

To identify the current indications of laparoscopic ovarian drilling and the best surgical technique that can be implemented as public health policies in order to enable the realization of individual life plans, especially with regard to the perpetuation of the species.

\section{Method}

A review of the medical literature available in the Medline, Lilacs and Cochrane Library databases was performed by selecting articles published on any date, on human beings, written in English, Portuguese or Spanish. The keywords used were laparoscopy, polycystic ovary syndrome, and drilling.

In all, 105 articles were found, their abstracts being read. We selected 27 of these articles: two meta-analyzes, two systematic literature reviews, nine reviews of the literature, seven randomized prospective studies, six retrospective cohort studies and one case series.

Studies involving treatment of polycystic ovaries with laparoscopic drilling that had as a main outcome the birth rate of live fetuses and multiple pregnancies were included. Secondary outcomes included miscarriage, ovulation rate, pregnancy rate, ovarian hyper-stimulation, quality of life and costs.

\section{RESULTS}

\section{Retrospective studies}

An Austrian study published in 2011 reviewed the results of a gynecological laparoscopy service at the University of Vienna in relation to the drilling technique with a monopolar hook. Thirty eight patients with PCOS resistant to clomiphene citrate (CC), that is, that did not ovulate after treatment with this medication and who had undergone surgical treatment were assessed. A monopolar hook was used to make three to six ovarian capsule per- forations in each ovary. This resulted in a $75.8 \%$ rate of spontaneous ovulation, a total rate of pregnancies in one year of $80.6 \%$, and subsequent $67.7 \%$ of live births. ${ }^{3}$

Hayashi et al. studied 40 patients with PCOS and resistance to $\mathrm{CC}$ who were treated with drilling. In the surgical procedure, 10 to 40 ovarian perforations were performed using electro-cauterization with Argon beam. The number of perforations depended on the size of the ovary. An ovulation rate of $83 \%$ and pregnancy rate of $55 \%$ were found after the procedure. It was also observed that preoperative serum levels of luteinizing hormone $(\mathrm{LH})$ were significantly higher among women who achieved ovulation after surgery, with a "cut-off" of $8 \mathrm{IU} / \mathrm{L} .{ }^{4}$

In 2011, a Chinese group retrospectively studied 89 infertile patients with PCOS who underwent laparoscopic drilling and were monitored for 5 years. The surgical procedure consists of three to 10 monopolar needle punctures measuring $2 \mathrm{~mm}$ in diameter and $8 \mathrm{~mm}$ in depth in both ovaries. The patients were placed into two groups: with metabolic syndrome and without metabolic syndrome, and the results were compared. The authors found no statistical difference in the spontaneous ovulation rate, cumulative rate of pregnancy and risk of gestational diabetes between the groups. Ovarian drilling was effective in inducing ovulation in PCOS patients regardless of whether they had metabolic syndrome or otherwise. After 16 months of follow-up, $61 \%$ of the patients had spontaneous ovulation and the cumulative pregnancy rate for the entire cohort was $63 \%$. There were 4 cases of multiple births, none of which resulted from spontaneous conception. ${ }^{5}$

In 2010, Johannes Ott et al. studied 120 patients with PCOS who become pregnant after some form of treatment for ovulation. Forty were resistant to CC and had spontaneous ovulation after laparoscopic drilling, while other 40 pregnant women obtained ovulation after stimulation with $\mathrm{CC}$, and the remaining 40 pregnant women ovulated after the use of metformin as an isolated therapy. LD was performed with a monopolar hook and 5 to 10 perforations of 2 to $3 \mathrm{~mm}$ in the capsule of each ovary bilaterally. The experimental group with CC realized an average of $1.6 \pm 0.8$ cycles of medication with dosages of 50 to $100 \mathrm{mg}$. Patients receiving metformin as a single treatment, used $1500 \mathrm{mg} /$ day for at least two months in order to become pregnant. There were no cases of ovarian hyper-stimulation and twin pregnancy rates were higher in the group receiving CC. When evaluating the totality of gestational complications, such as miscarriages, premature births, birth defects, development of preeclampsia or gestational diabetes, the following occurrence the was found: $70 \%(28 / 40)$ in the CC 
group, $45 \%(18 / 40)$ in the LD group and $47.5 \%(19 / 40)$ in the metformin group. ${ }^{6}$

In another retrospective study, Johannes Ott et al. evaluated whether the levels of FSH, LH, testosterone and androstenedione could act as predictors of spontaneous ovulation after LD. They retrospectively studied 100 PCOS patients resistant to CC in which hormone levels were measured (FSH, LH, testosterone and androstenedione) prior to laparoscopic drilling. Cut-off values were set to $12.1 \mathrm{IU} / \mathrm{L}$ for $\mathrm{LH}$ and $3.26 \mathrm{ng} / \mathrm{mL}$ for androstenedione. Sixty-three of the seventy (90\%) patients with high LH ovulated in the first three months of follow-up after drilling. Thirty-six of the $42(85.7 \%)$ patients with elevated LH and androstenedione ovulated spontaneously during the same period. Among the patients with LH or androstenedione below the cut-off, $8 / 30$ (26.7\%) had spontaneous ovulation and 35/58 (60.31\%) ovulated, respectively. When both low LH and androstenedione were considered together, $0 / 31$ patients achieved ovulation. The surgical technique used was 5 to 10 punctures in each ovary with a monopolar hook.?

An European study also tried to find predictors of success for laparoscopic drilling, evaluating 200 patients undergoing surgical treatment. The surgical technique used was 3 to 10 punctures in each ovary, $4 \mathrm{~mm}$ in diameter and $7 \mathrm{~mm}$ deep. The same authors had previously demonstrated that the performance of only two punctures in each ovary was not sufficient to induce ovulation. ${ }^{8} \mathrm{~Pa}-$ tients with body mass index (BMI) values greater than 35 $\mathrm{kg} / \mathrm{m}^{2}$ obtained lower ovulation rates $(13 \%)$ compared to patients with BMI between 29 and $34 \mathrm{~kg} / \mathrm{m}^{2}(46 \%)$ and those with BMI $<29 \mathrm{~kg} / \mathrm{m}^{2}(57 \%)$. However, the pregnancy rate had no statistical significance between the groups. As for serum testosterone levels, the authors noted that among those with high levels $(\geq 4.5 \mathrm{nmol} / \mathrm{L})$, the ovulation rate was $10 \%$, significantly lower than among those with moderate levels of testosterone (2.6 to $4.4 \mathrm{nmol} / \mathrm{L}$ ), which was $48 \%$, and normal testosterone $(2.6 \mathrm{nmol} / \mathrm{L})$, with a $56 \%$ ovulation rate. Increasing rates were observed for ovulation and pregnancy the higher the serum levels of LH (> $10 \mathrm{IU} / \mathrm{L}$ ). On the other hand, there was no association between the LH/FSH ratio, the presence or absence of acne, menstrual pattern or ovarian volume, and post-drilling rates of ovulation and pregnancy. ${ }^{9}$

\section{Clinical trials}

A new laparoscopic drilling modality was published in 2013 by Salah, in which the procedure is performed using mini-laparoscopy with instruments measuring $3.5 \mathrm{~mm}$ and local anesthesia. The procedure was performed in 60 patients in an outpatient setting, with a very low pain score and early release of 2 hours. There was no difference in pregnancy rates compared to the conventional laparoscopy technique with punctures of 10 and $5 \mathrm{~mm}$ under general anesthesia. ${ }^{10}$

In 2011, Zakirah evaluated whether adjusting the thermal dose used in $\mathrm{LD}$ according to the ovarian volume resulted in better reproductive results than using a fixed thermal dose. In 60 patients he used $60 \mathrm{~J}$ per $\mathrm{cm}^{3}$ of ovarian tissue, while in other 60 patients he used a fixed thermal dose of $600 \mathrm{~J}$. Four perforations were made to each ovary. The researcher found that return to regular menstrual cycles, as well as ovulation and pregnancy rates were higher in the group receiving a dose adjusted to the ovarian volume. As for abortion rates and postoperative adhesions, there was no difference between groups. ${ }^{11}$

Hamed et al. compared the treatment of chronic anovulation caused by PCOS with CC resistance using drilling (55 patients) or metformin alone (55 patients). They found that the group of drilling obtained a higher rate of menstrual cycle regularization, as well as higher rates of ovulation and pregnancy. There was $76.4 \%$ regularization of menstrual cycles in the LD group versus $58.2 \%$ in the metformin group; $50.8 \%$ ovulation in the $\mathrm{LD}$ group versus $33.5 \%$ in the metformin group and $38.2 \%$ pregnancy rate in the LD group versus $20 \%$ in the metformin group. The metformin group had greater attenuation of insulin resistance. ${ }^{12}$

A prospective study of 44 patients aimed at assessing whether unilateral laparoscopic drilling caused less fimbrial-tubal adhesion and, therefore, a higher pregnancy rate than the conventional technique with perforations in both ovaries. The patients were allocated into two groups: 22 patients were subjected to conventional drilling with 5 perforations in each ovary and the other 22 patients were subjected to unilateral drilling with 5 perforations in one ovary. The ovulation and pregnancy rate was similar between the groups. However the frequency of tubal adhesions observed during a second laparoscopy or during cesarean delivery was higher in the bilateral drilling group. ${ }^{13}$

Another Italian study evaluated the association between the number of punctures in the ovaries and the occurrence of ovarian adhesions. Forty-eight patients underwent laparoscopic drilling with 6 perforations in the left ovary and 12 perforations in the right ovary, and the other 48 patients were submitted to the contrary ( 12 holes in the left ovary and 6 holes in the right ovary). All patients underwent micro-laparoscopy for a second-look. The formation of adhesions was noted in $90(60 \%) \mathrm{pa}-$ 
tients. The adhesions were significantly more frequent in the left ovary regardless of the number of perforations. ${ }^{14}$

In 2005, Malkawi published a study comparing the realization of 5 or 10 bilateral ovarian punctures in relation to regulating menstrual cycle, ovulation rate and pregnancy. For this purpose, 26 patients were submitted to LD with 5 perforations in each ovary and 37 patients to LD with 10 bilateral punctures. There was no statistically significant difference in relation to clinical and reproductive results between the groups. ${ }^{15}$

\section{Case series}

In 2010, the University of Paris described a new technique for ovarian drilling using bipolar energy. Ninety patients underwent laparoscopy under general anesthesia with a $10 \mathrm{~mm}$ infraumbilical puncture and two suprapubic punctures measuring $3 \mathrm{~mm}$ each. A bipolar electrosurgical Versapoint probe by Johnson \& Johnson was used, in addition to continuous saline irrigation to activate the bipolar energy. The entire electrode length $(15 \mathrm{~mm})$ was inserted into the ovary at right angle, with pure cut coagulation and $100 \mathrm{~W}$. The current was turned on for 2 seconds and eight to 10 punctures were performed in each ovary. The main outcome of the surgical LD techniques is always spontaneous ovulation and pregnancy rates. The follow-up of these series was too short to evaluate such results. ${ }^{16}$

\section{Literature reviews and meta-analysis}

The Cochrane Library updated a review whose purpose was to determine the effectiveness and safety of laparoscopic ovarian drilling compared to other ovulation induction techniques in PCOS patients resistant to clomiphene citrate. Twenty-five randomized clinical trials were included. The primary outcome was the rate of live birth and multiple pregnancies. Secondary outcomes included miscarriage, ovulation rate, pregnancy rate, ovarian hyper-stimulation, quality of life and costs. Nine clinical trials including 1,210 women reported live birth rates of $34 \%$ after $\mathrm{LD}$, and $38 \%$ in the other treatment groups (CC tamoxifen, gonadotropins, aromatase inhibitors; CC; CC metformin). There was no difference in the rate of live births when comparing $\mathrm{LD}$ and $\mathrm{CC}$ tamoxifen $(\mathrm{OR}=0.81 ; \mathrm{p}=0.51) ; \mathrm{LD}$ with gonadotropins $(\mathrm{OR}=0.97 ; \mathrm{P}=0.89)$; $\mathrm{LD}$ with aromatase inhibitors $(\mathrm{OR}=0.84 ; \mathrm{p}=0.44)$ and $\mathrm{LD}$ with $\mathrm{CC}(\mathrm{OR}=1.21$; $\mathrm{p}=0.05$ ). There was evidence of a lower rate of post-LD live births compared to the group treated with CC metformin $(\mathrm{OR}=0.44 ; \mathrm{p}=0.01)$; however, there was a lot of heterogeneity in this subgroup. Thirteen clinical trials made reference to multiple pregnancies $(n=1,305)$. The rate of multiple pregnancies after $\mathrm{LD}$ was significantly lower compared to that of the group using gonadotropins $(\mathrm{OR}=0.13 ; 95 \mathrm{CI}$ 0.03 to $0.52 ; \mathrm{p}=0.004)$. The authors concluded that there is no evidence of significant difference in the rates of pregnancy, live birth or abortion in women resistant to CC treated with LD compared to other medical therapies for anovulation. The reduction in multiple pregnancy rates makes surgical treatment an attractive option. ${ }^{17}$

A literature review conducted by a research center in Istanbul, Turkey studied trauma after ovarian drilling with the possibility of decreased ovarian reserves and premature failure of the organ. Despite the data from the literature being very limited (only four clinical trials), the author found that FSH, inhibin, ovarian volume and antral follicle count were worse after LD than before the procedure. However, the values after drilling were higher than those of normal women with the same characteristics, that is, without PCOS. Thus, the authors concluded that most changes in markers of ovarian reserves after drilling are due to the normalization of ovarian function and not to a decrease in reserves. When applied properly, LD normalizes exaggerated ovarian morphology, as well as endocrine properties. ${ }^{18}$

\section{Discussion}

Ovulation disorders are the leading cause of female infertility and PCOS is the most common etiology, often associated with being overweight or obese. It is well established that changes in lifestyle with the practical introduction of physical exercise and weight loss improve hyperandrogenism, decrease insulin resistance, reduce LH levels and may restore ovulation and, therefore, fertility. ${ }^{19}$ In addition to these measures, the first line drug treatment for chronic anovulation is clomiphene citrate. And for those patients whose ovulation attempts fail after CC, new therapies are indicated, such as gonadotropins or ovarian drilling. ${ }^{20,21}$ The use of metformin seems to improve the response to clomiphene, though it should be prescribed with caution to non-obese patients. ${ }^{22}$ The surgical approach has been a strong option constituting the second-line treatment. ${ }^{23}$

Many forms of ovarian drilling are described, including electrocautery or laser use. All of these share a common goal, which is creating focal areas of damage in the ovarian cortex. There is no evidence that one method consistently produces results superior to another. Nevertheless, the use of laser therapy has become less popular. The method most commonly used worldwide at the moment is monopolar needle or hook due to ease of installation and the wide availability of the necessary equipment. ${ }^{24}$ 
In 2003, Izzo and Halbe found reduced ovarian volume after $\mathrm{LD}$, with reduced serum levels of testosterone and androstenedione, without interference in the level of gonadotropins. The post DL pregnancy rate was similar to that obtained after ovulation induction cycles with recombinant follicle stimulating hormone. ${ }^{25}$ In addition to providing similar conception rates compared to the use of gonadotropins, laparoscopic drilling does not require monitoring of the cycle. With a single surgical treatment, several cyclical ovulations can be obtained, whereas one gonadotropin cycle yields a single ovulation cycle. A study conducted in New Zealand showed that the cost to achieve a live birth after ovulation induction with gonadotropins is two-thirds higher than that obtained using a surgical treatment. ${ }^{26}$ Thus, the best advantage of LD is its simplicity and effectiveness as a method. Regarding the risks, these are inherent to all abdominal surgical procedures, and include the risks of anesthesia, injury to the bowel, bladder, blood vessels, infection and formation of postoperative adhesions.

The long-term (over five years) effect of LD is unknown, so it seems prudent to recommend the procedure only to patients who are decidedly seeking pregnancy. There is no data relating LD with menopause but epidemiological studies show early menopause in women undergoing any type of surgery with reduction of the ovaries. Another factor that contributes to the reduced number of surgical patients is the use of agents that reduce insulin resistance, allowing ovulation in patients previously resistant to $\mathrm{CC} .{ }^{27}$ We should also consider that candidates for laparoscopic drilling should not present factors of infertility other than polycystic ovary syndrome, which would make treatment little or non-effective.

The balance of risks and benefits between $\mathrm{LD}$ and the use of gonadotropins appears somewhat similar. Due to the invasiveness of the surgical method, some patients may opt for clinical induction of ovulation despite an increased risk of hyper-stimulation and multiple pregnancies. Laparoscopic ovarian drilling is an attractive option in selected cases. ${ }^{28}$

Therefore, LD should not be discarded in the preparation and implementation of health policies for the treatment of human infertility, in order to ensure maximum effectiveness of the law (constitutional) for family planning (article 226, paragraph 7 of the Brazilian Constitution). The decision to have children should be taken in the scope of people's private lives, without any form of coercion by the State, but it is up to the State to offer conditions for families to be able to decide whether to have children, independently and with clarification, with the help of scientific techniques of contemporary medicine. ${ }^{29}$

\section{Conclusion}

Laparoscopic drilling may be indicated for patients with PCOS and ovulatory resistance to the use of clomiphene citrate.

As for the surgical technique, studies in the literature are very heterogeneous, hindering this type of analysis. It is not possible to identify an optimal surgical technique. However, the most successfully used technique is performing 5 to 10 perforations to the surface of the ovary, bilaterally, using monopolar energy.

\section{Resumo}

Drilling: indicações e técnica

Introdução: a anovulação é uma das principais causas de infertilidade feminina, e a síndrome dos ovários policísticos (SOP) é a principal causa de anovulação. As mulheres com SOP, quando submetidas a indução medicamentosa da ovulação, costumam ter resposta satisfatória, recrutando folículos. No entanto, algumas podem não recrutar folículos ou, muitas vezes, têm uma produção excessiva deles, o que pode resultar em síndrome de hiperestímulo ovariano e/ou gravidez múltipla. O tratamento cirúrgico por laparoscopia com drilling ovariano pode evitar ou reduzir a necessidade de indução da ovulação com medicamentos.

Objetivos: identificar as indicações atuais do drilling ovariano laparoscópico e qual a melhor técnica operatória.

Método: revisão da literatura médica, por meio de busca sistemática nas bases de dados MEDLINE, LILACS e Cochrane, utilizando as palavras-chave: laparoscopia, síndrome dos ovários micropolicísticos e drilling.

Resultados: foram encontrados 105 artigos na literatura, sendo 27 de grande relevância descrevendo achados sobre o drilling ovariano.

Conclusão: o drilling laparoscópico está indicado para pacientes com SOP com resistência ovulatória ao uso do citrato de clomifeno, índice de massa corpórea (IMC) inferior a $30 \mathrm{~kg} / \mathrm{m}^{2}$ e hormônio luteinizante (LH) pré-cirúrgico superior $10 \mathrm{UI} / \mathrm{L}$. A técnica operatória de preferência deve ser a realização de 5 a 10 perfurações na superfície de cada ovário bilateralmente por meio do uso de energia monopolar.

Palavras-chave: clomifeno, laparoscopia, anovulação, síndrome do ovário policístico, perfuração de percussão.

\section{References}

1. Mitra S, Nayak PK, Agrawal S. Laparoscopic ovarian drilling: an alternative but not the ultimate in the management of polycystic ovary syndrome. J Nat Sci Biol Med. 2015; 6(1):40-8. 
2. Costello MF, Ledger WL. Evidence-based management of infertility in women with polycystic ovary syndrome using surgery or assisted reproductive technology. Womens Health (Lond Engl). 2012; 8(3):291-300.

3. Ott J, Mayerhofer K, Aust S, Nouri K, Huber JC, Kurz C. A modified technique of laparoscopic ovarian drilling for polycystic ovary syndrome using the monopolar hook electrode. Acta Obstet Gynecol Scand. 2011; 90(5):547-50

4. Hayashi H, Ezaki K, Endo H, Urashima M. Preoperative luteinizing hormone levels predict the ovulatory response to laparoscopic ovarian drilling in patients with clomiphene citrate-resistant polycystic ovary syndrome. Gynecol Endocrinol. 2005; 21(6):307-11.

5. Kong GWS, Cheung LP, Lok IH. Effects of laparoscopic ovarian drilling in treating infertile anovulatory polycystic ovarian syndrome patients with and without metabolic syndrome. Hong Kong Med J. 2011; 17(1):5-10.

6. Ott J, Kurz C, Nouri K, Wirth S, Vytiska-Binstorfer E, Huber JC, et al. Pregnancy outcome in women with polycystic ovary syndrome comparing the effects of laparoscopic ovarian drilling and clomiphene citrate stimulation in women pre-treated with metformin: a retrospective study. Reprod Biol Endocrinol. 2010; 8:45

7. Ott J, Wirth S, Nouri K, Kurz C, Mayerhofer K, Huber JC, Tempfer CB. Luteinizing hormone and androstendione are independent predictors of ovulation after laparoscopic ovarian drilling: a retrospective cohort study. Reprod Biol Endocrinol. 2009; 7:153.

8. Amer SAK, Li TC, Cooke ID. Laparoscopic ovarian diathermy in women with polycystic ovarian syndrome: a retrospective study on the influence of the amount of energy used on the outcome. Hum Reprod. 2002; 17(4):1046-51.

9. Amer SAK, Li TC, Ledger WL. Ovulation induction using laparoscopic ovarian drilling in women with polycystic ovarian syndrome: predictors of success. Hum Reprod. 2004; 19(8):1719-24.

10. Salah IM. Office microlaparoscopic ovarian drilling versus conventional laparoscopic ovarian drilling for women with polycystic ovary syndrome. Arch Gynecol Obstet. 2013; 287(2):361-7.

11. Zakherah MS, Kamal MM, Hamed HO. Laparoscopic ovarian drilling in polycystic ovary syndrome: efficacy of adjusted thermal dose based on ovarian volume. Fertil Steril. 2011; 95(3):1115-8.

12. Hamed HO, Hasan AF, Ahmed OG, Ahmed MA. Metformin versus laparoscopic ovarian drilling in clomiphene and insulin-resistent women with polycystic ovary syndrome. Int J Gynaecol Obstet. 2010; 108(2):143-7.

13. Roy KK, Baruah J, Moda N, Kumar S. Evaluation of unilateral versus bilateral ovarian drilling in clomiphene citrate resistant cases of polycystic ovarian syndrome. Arch Gynecol Obstet. 2009; 280(4):573-8.
14. Mercorio F, Mercorio A, Di Spiezo Sardo A, Barba GV, Pellicano M, Nappi C. Evaluation of ovarian adhesion formation after laparoscopic ovarian drilling by second-look minilaparoscopy. Fertil Steril. 2008; 89(5):1229-33.

15. Malkawi HY, Qublan HS. Laparoscopic ovarian drilling in the treatment of polycystic ovary syndrome: how many punctures per ovary are needed to improve the reproductive outcome? J Obstet Gynaecol Res. 2005; 31(2):115-9.

16. Fernandez H, Faivre E, Gervaise A, Deffieux X. Laparoscopic ovarian drilling using a 5-French bipolar energy probe. Fertil Steril. 2010; 94(2):740-1.

17. Farquhar C, Brown J, Marjoribanks J. Laparoscopic drilling by diathermy or laser for ovulation induction in anovulatory polycystic ovary syndrome. Cochrane Database Syst Rev. 2012; 6:CD001122.

18. Api M. Is ovarian reserve diminished after laparoscopic ovarian drilling? Gynecol Endocrinol. 2009; 25(3):159-65.

19. Messinis IE. Ovulation induction: a mini review. Human Reproduction. 2005; 20(10):2688-97.

20. Propst AM, Bates GWJr. Evaluation and treatment of anovulatory and unexplained infertility. Obstet Gynecol Clin North Am. 2012; 39(4):507-19.

21. Bates GW Jr, Prospt AM. Polycystic ovarian syndrome management options. Obstet Gynecol Clin North Am. 2012; 39(4):495-506.

22. Misso ML, Costello MF, Garrubba M, Wong J, Hart R, Rombauts L, et al. Metformin versus clomiphene citrate for infertility in non-obese women with polycystic ovary syndrome: a systematic review and meta-analysis. Hum Reprod Update. 2013; 19(1):2-11.

23. Grzegorczyk MV, Belaisch-Allart J. The place of ovarian drilling in the management of polycystic ovarian syndrome. Gynecol Obstet Fertil. 2011; 39(9):518-20.

24. Api M. Is there any difference among the most frequently used laparoscopic ovarian drilling techiniques? Fertil Steril. 2009; 91(6):e9.

25. Izzo CR. Contribuição da eletrocauterização laparoscópica ovariana bilateral no tratamento de mulheres inférteis com síndrome dos ovários policísticos clomifeno-resistentes. Rev Bras Ginecol Obstet. 2003; 25(8):614-5.

26. Farguhar CM. An economic evaluation of laparoscopic ovarian diathermy versus gonadotrophin therapy for women with clomiphene citrate-resistant polycystic ovarian syndrome. Curr Opin Obstet Gynecol. 2005; 17(4):347-53

27. Mayenga JM, Grzegorczyk MV, Belaisch-Allart J. The place of ovarian drilling in the management of polycystic ovarian syndrome. Gynecol Obstet Fertil. 2011; 39(9):518-20.

28. Catenacci M, Goldberg JM. Transvaginal hydrolaparoscopy. Semin Reprod Med. 2011; 29(2):95-100

29. Moraes MCD, Teixeira ACB. O planejamento familiar. In: Canotilho JJG (org.) Comentários à Constituição do Brasil. São Paulo: Saraiva/Almedina; 2013. p.2122 